\title{
Reflection in Class: Experimenting with Text
}

\author{
Gayane Girunyan \\ Yerevan State University
}

\begin{abstract}
Methodological studies, as well as teaching practice attest to the central role of reflective thinking in class. As a fundamental skill, which once learned is applicable to any domain of knowledge, reflection is the prerequisite of critical thinking - a goal university education pursues too. The paper stresses the importance of practical assignments as part of the course of Text Linguistics and presents an experimental model involving verbalization of graphical texts and meta-cognitive awareness through guiding questions. With a focus on both individual and shared experience, the role of emotional response is viewed as a motivating factor.
\end{abstract}

Key words: meta-cognitive skills, educational goals, textuality, creativity.

\section{Introduction}

If asked, every teacher will be ready to present a long list of observations, their own findings and useful hints on conducting a lesson, stressing at the same time that the students are always different: whether individually or even at the group level. There is no doubt that the teacher is never the same either - I mean that the special atmosphere that is created in and with every class is unique, being such due to collective effort and developing throughout the course. Moreover, the content of the course and the domain of specialized knowledge that the latter covers are significant too.

Having taught university courses for more than two decades, I have arrived at some awareness of the process ("some" - because my practice is an ongoing experience), five aspects of which have always seemed important to me. The first is the awareness of the educational goals in general, and in particular, the formation of so-to-call "working knowledge" to be derived from each course. The second is the awareness of teaching/learning as communication, in which the roles of teacher and learner can reciprocally change in the sense that not only is the student the learner but the teacher as well. I would summarize the 
exchange of the roles as: "Whoever asks the question is the teacher", firmly believing that we learn from our students, by considering their perspectives, their simple or thoughtful questions. The third aspect that I would stress is the importance of reflective thinking and hence, use of reflective skills in the teaching/learning process both by the teacher and student, that is, both sides involved in the communication need meta-cognitive skills. The fourth is the understanding that reflection is a creative process including such components as generating, planning, and producing, to help which - elements of artistic creativity can be applied. Finally, knowledge is not merely "borrowed" as information, but is learnt, that is, experienced, the experiential character of reflection being obvious too.

\section{Educational Goals}

The recognition by educational theorists of the demand that educational objectives should be classified and presented in a systematic and consistent way brought to the publication of frameworks known as taxonomies: "Taxonomy of Educational Objectives: The Classification of Educational Goals. Handbook I: Cognitive Domain" (1956) by Benjamin S. Bloom and the later publication by Anderson, Krathwohl and their co-authors of "A Revision of Bloom's Taxonomy" (2001). As Krathwohl observes, as different from the original taxonomy with its distinct categories in the cognitive domain (Knowledge, Comprehension, Application, Analysis, Synthesis, Evaluation), presented as a cumulative hierarchy whose categories are distributed from concrete to abstract and simple to complex, the Revised version introduced a new category in the knowledge dimension - meta-cognitive knowledge (Krathwohl 2002), which, according to the authors of the revised system, "involves knowledge about cognition in general as well as awareness of and knowledge about one's own cognition." Krathwohl also points to the "increasing significance" of such knowledge in making students "aware of their meta-cognitive activity and then using this knowledge to appropriately adapt the ways in which they think and operate" (Krathwohl 2002:214). As presented in the new taxonomy, it is strategic knowledge, knowledge about cognitive tasks, contextual and conditional knowledge and self-knowledge. In other words, it is what is obtained by reflective thinking.

The introduction of the new category is not the only change in the framework: the revised taxonomy tends to stress the dynamic nature of 
knowledge acquisition (cf.: the choice of verb forms, apply rather than application, analyze instead of analysis, evaluate in place of evaluation); it is a "two-dimensional framework" with Knowledge and Cognitive Process as the parameters (Krathwohl 2002:218); the structure of the cognitive process dimension is more detailed. The changes included in the revised version of the taxonomy are not formal, but are indicative of a more profound understanding of the process. I would single out two positions.

The first is the substitution of the term understand for comprehension: a convincing choice, considering the presence of meta-cognitive activity (reflective thinking), and of such modes as interpreting and explaining handled on a par with understanding in hermeneutical tradition. In the revised framework, the category of Understand is represented by: Interpreting, Exemplifying, Classifying, Summarizing, Inferring, Comparing and Explaining. Moreover, the very definition of Understand as "determining the meaning of instructional messages, including oral, written and graphic communication" (Krathwohl 2002:215) does not overlook the communicative character of the process (cf.: understanding of texts as communication/ hermeneutical dialogue).

The second is the use of the term create instead of synthesis, where the category Create comprises such constituents as Generating, Planning, Producing, and is defined as: "putting elements together to form a novel, coherent whole or make an original product" (Krathwohl 2002:215). In this case also the decision on the more inclusive and more representative term is justified, Understanding/Interpreting/Explaining involving awareness of the correlation between part and whole (cf.: hermeneutical circle) and demanding creative response. Besides, the choice of the term allows not only the technical sense of "putting elements together to form a coherent or functional whole; that is, reorganizing elements into a new pattern or structure" (Mayer 2002:231) but also the notion of it as denoting artistic/inventive/playful creativity.

\section{Teaching/Learning as Communication}

The main outcome of education (and especially university education) being "working knowledge", its aim is much wider - a process, which Richard E. Mayer calls "meaningful learning" (2002). Describing the different aspects of the cognitive process specified in the Revised Taxonomy - Remember, Understand, Apply, Analyze, Evaluate, Create - the theorist makes a further 
generalization, and namely that the first promotes retention, and the remaining five - transfer.

In other words, the distinction is based on two mechanisms: of storing knowledge, and that of using it, with creating new knowledge (on a larger scale) as the climax of the second process. In simpler terms, it is at the heart of the dilemma that we face when assessing our students' performance: who is the better - the one who remembers the material well (often even verbatim) or the one who may not remember details but produces his/her own interpretation?

Mayer defines transfer as "the ability to use what was learned to solve new problems, answer new questions, or facilitate learning new subject matter" (Mayer 2002:226). In pursuit of this highly-demanding aim, two things should not be overlooked. The first is that "meaningful learning" is communication, in the most profound sense of the word, between two sides, and I would call them worlds, systems, laboratories, which are understood as roles, and which being relative parts cannot exist without each other. As mentioned earlier, these roles change alternately between teaching and learning, and the process can be successful only if the efforts are well-balanced, i.e. if both sides make their earnest contribution to it.

The next decisive factor is openness on both parts to each other's initiative. Needless to say, feeling determined, and motivated to share with their students their expertise and general background, teachers will often choose to experiment with the material, activities, method of teaching. When I was reflecting on the type of activities that I have chosen to practice in class, I was encouraged by A. Ball's conclusion paraphrased by Choy and Oo that "teachers with high self-efficacy are those that have high meta-cognitive awareness of themselves and can change the strategies they are using to attain their intended goals" (Choy and Oo 2012:170).

\section{Learning and Reflection}

The reflective and creative type of activities presented below are meant as part of the course of Text Linguistics, and the motivation to present it for consideration was supported by two generalizations, to which my own teaching practice attests too. They are: "Reflection, once learned is a skill that crosses disciplines", and therefore, it is "content neutral" (Colley et al 2012:1).

I do not intend to claim that a university student is not familiar with reflective learning, rather that such activities should be continued at a higher 
level of theoretical knowledge and with elements of imaginative creativity. The idea is that even with the more conscious choice of specialization, learners need motivation, and the shortest way is through reflection as experience where "emotional responses are part of what we bring to every learning situation and should be brought to the surface and examined" (Colley et al 2012:5).

As for the teacher's perspective, the most sincere wish on his/her part is to improve the process of instruction, and for that purpose, as James Raths suggests, the two ways, which the Revised Taxonomy allows, are: 1) focus on "increasingly more complex cognitive processes, particularly Analyze, Evaluate, Create", and 2) "objectives that emphasize meta-cognitive knowledge" (Raths 2002:235). As for the latter, Paul R. Pintrich summarizes the findings of researchers that, as students "become more aware of their own thinking", "they tend to learn better" (Pintrich 2002:219).

One of the major elaborations on reflection is John Dewey's conception in "How We Think" (1910/1933), discussing which Carol Rodgers focuses on four criteria, which she thinks characterize his position. Briefly, the first is that reflection is a meaning-making process with essentially moral ends; secondly, that it is a "systematic, rigorous, disciplined way of thinking, with its roots in scientific inquiry"; thirdly, it "needs to happen in community, in interaction with others"; and finally, that it requires evaluative attitudes (Rodgers 2002:845). Thus, the human, i.e. intellectual, moral and communicative/interactive sides are stressed, without which the process of learning - whether at the individual or group level - would be unthinkable. On the whole, agreeing with the conclusions, and in particular that "systematic", "rigorous", having "roots in scientific inquiry" do apply to reflection, I would argue that the latter is not confined to those processes.

Rodgers also mentions that for Dewey belief, invention and stream of consciousness are kinds of thought different from reflection (Rodgers 2002:849). I am inclined to think that reflection being the best representative mode in terms of logical reasoning, these should not be contrasted as it is hardly possible to view them in isolation from each other, considering that thinking as totality is not a sum of fragments, and that spontaneous, subconscious, inventive and emotional elements may occur in essentially systematic and consistent reflection as well. Furthermore, the learner's and teacher's awareness of their selves, beliefs, inventive thoughts, emotional-evaluative response, etc., can trigger a more "systematic" and "rigorous" process. 
One last remark concerning the creative/inventive component: as a meaningmaking, and hence creative process (typically expressed by means of verbal language), reflection, however, should not be reduced to the domain of concepts only. And as long as we acknowledge its experiential nature, we could not overlook the other dimension that creativity has - artistic, with its own textuality and even more "delicate forms of reflection" - to use Dennis S. Schmidt's wording (Schmidt 2013:8). Exposed to interpretation and as unique forms of artistic reflection, such compositions are human texts, and the way we understand them, citing Dennis Schmidt again, "is not necessarily wedded to the intelligibility defined by conceptuality. Insofar as images can constitute a text that is, insofar as they can lay claim to being intelligible and understandable one must take seriously the process that the word does not define the realm of the intelligible. Textuality is a way in which one can recognize and account for an intelligibility not restricted to linguistic and conceptual forms of intelligibility" (Schmidt 2013:20).

I would also add that my personal experience of creative reflection is that there are states starting from and returning to which I prefer to produce images, thinking about which helps me understand my search for meaning better. On the other hand, these states which are neither yet finally formulated thought nor still finally shaped image, are important for me as I enjoy the freedom from being mistaken, or from misunderstanding, even from being misunderstood. These are states of experimenting with my own text, not much restricted by formal convention. One such recent paper is "Cross-Cultural Perspective: An Attempt at Bimodal Reflection" (Girunyan 2015).

\section{Creative Reflection as Experience:}

\section{Experimenting with Interpretation and Explanation}

On the basis of what has been said so far and also considering the fact that the field of textual studies is interdisciplinary, and hence extensive, it is suggested that the course should include practical assignments/activities of creative and reflective character which will help to develop the feel of "knowing from experience" for the discussion and theorizing of diverse textual phenomena not to seem too abstract or "out of reach". In particular, such fundamental issues as textuality, communication, multimodality, interdiscursivity, as well as more specific ones such as coherence, cohesion, etc., will be handled as immediate observations if the students are asked to reflect on 
their own, each other's or the teacher's discourse. The same refers to the teacher's perspective.

Thus, for the start the students will be asked to produce their own descriptive texts as verbalizations of graphical images, i.e. translate images into verbal language, at the same time feeling free in the process to include not only factual and concrete details but also their own chains of associations. For such activities nearly any graphical material (e.g. images of places, people, events, etc.) can be useful from the perspectives of defining contexts of situation, compositional structure, informativity, and other parameters defining a text in general. And I firmly believe that the material of study should be extended to include artistic compositions, where the freedom of associations is greater and the reflective process finer. Obviously, in such cases the students taking on the role of interpreter will focus on their own experience: perception, attitude, etc. along with the shared part of background (knowledge). It is expected that when shaping their verbalized versions, they will strive to make their texts coherent and well-formed.

The variety of pieces and their further exchange and analysis should be a rewarding experience both for the students and the teacher, and the complexity of the material for discussion may be increased to stress this or that aspect of textuality.

Well aware of the fact that it is impossible to cover the variety of choices of material in this paper, and also hoping that the statement of the idea is selfexplanatory, I will present an experimental class activity, in which I have my own part of personal involvement. Motivated to hear and discuss my students' response to my attempt at visual text production (collages/installations created as artistic compositions), I anticipate their readiness to reflect on their own experience.

Thus, the activity involves two stages, the first of which is text production with the awareness of the transition from image to verbal text. The second is the reflective consideration of the results. Both stages are guided by questions initiated by the teacher, and further answered and/or revised by the students. With the understanding of openness for communication in mind, I am also ready to answer their questions (including ones about the compositions). In other words, the uniting factor for everyone will be reflection' I have tried such a sharing of experience with smaller groups within the course of Academic English and now believe that it could be especially useful for Text Linguistics. 
Below is the image of my collage as a graphical text, followed by some examples of guiding questions (the latter forming an open-end set with possible variation) for the two-stage activity referred to above.

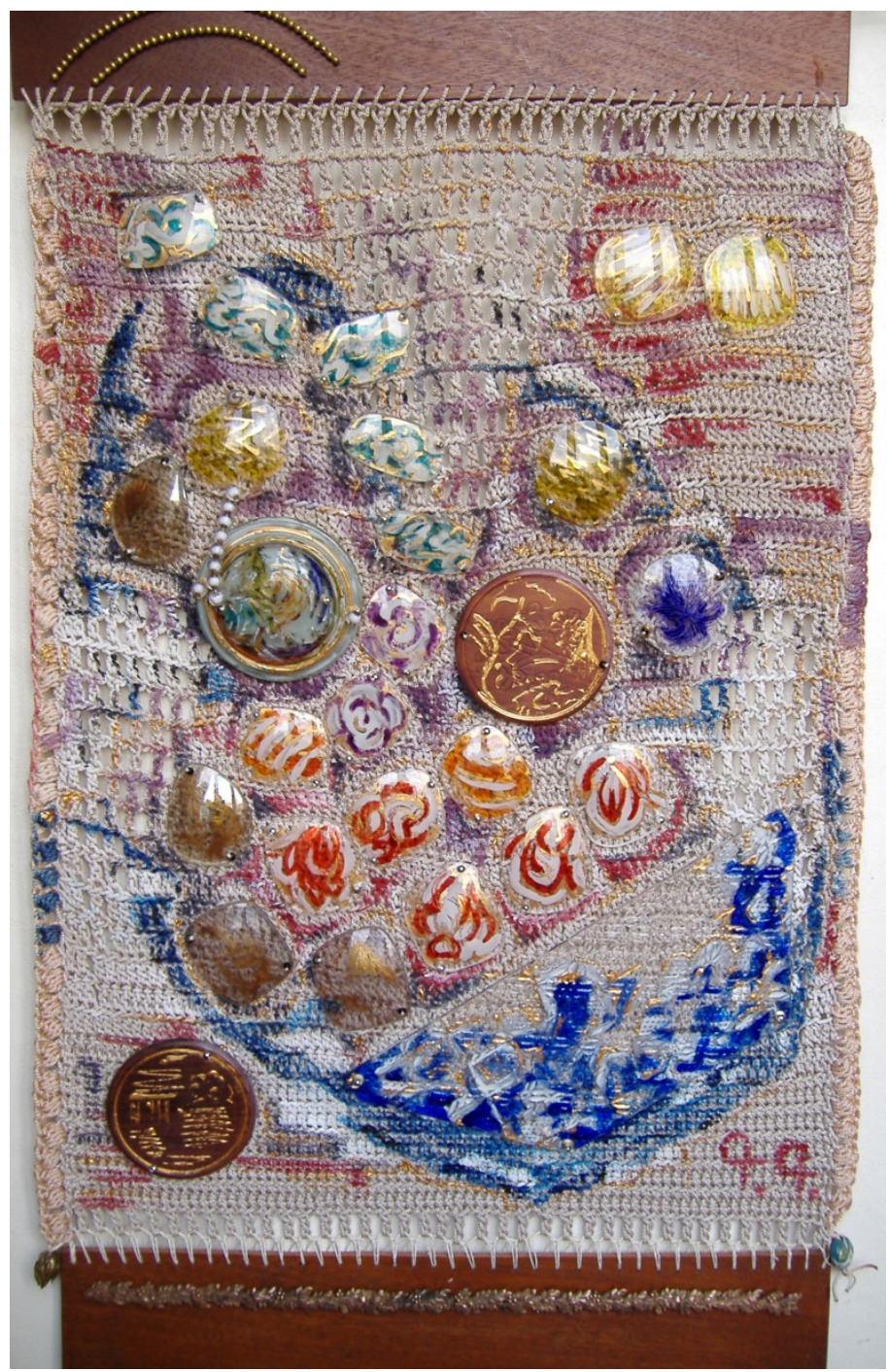

\section{Stage 1 - text production:}

$\checkmark$ What is the first thing that you notice about the visual text as a compositional whole? 
$\checkmark$ Describe the image in structural terms, focusing on the elements, the way they are combined.

$\checkmark$ Are there any unusual elements or structural features, and why do you think they might be included in the composition?

$\checkmark$ Pay attention to the techniques and the use of shapes, colours, materials.

$\checkmark$ What do you find as most/least appealing?

$\checkmark$ Does the image look unexpected/paradoxical/meaningful/polysemous to you?

$\checkmark$ Is there anything you would like to change about the collage? Why?

$\checkmark$ What would you preserve in the structure/composition of the collage if you were to make any changes?

$\checkmark$ Do you find anything familiar in the text, i.e. is the image reminiscent of anything else that you have seen, read, felt, etc.?

$\checkmark$ Are there any artistic or literary associations in your mind?

$\checkmark$ Are you thinking of figurative and/or symbolic dimensions?

$\checkmark$ Think of a context in which to set the image, i.e. of a "gallery" of other images.

$\checkmark$ Is the visual text a state/story/mood, etc. to you?

$\checkmark$ What would you ask the author about?

$\checkmark$ Think of a caption for the image: the choice might range from concrete to abstract, including the option "Untitled".

\section{Stage 2 - reflection on the verbalized text; discussion:}

$\checkmark$ Comment on your use of figurative language and analogies. Could you do without them?

$\checkmark$ Pay attention to your use of evaluative adjectives.

$\checkmark$ Looking back at the process, how often did you need to shift to your first language? What accounts for such shifts: lack of vocabulary, associations, or any other factors?

$\checkmark$ Did words happen to fail you, and if so, what did you feel like doing?

$\checkmark$ Is the text you have produced coherent?

$\checkmark$ What cohesive means have you used?

$\checkmark$ Specify your text in terms of genre.

$\checkmark$ Comment on your text in terms of lexical choice, stylistic means, etc.

$\checkmark$ Does your text look like a collage? 
$\checkmark$ Comment on the connection between the caption and your use of words from related lexical/semantic fields.

$\checkmark$ Do you think your text is more informative than the graphical one?

$\checkmark$ If you have told a story, is it what you have experienced, or heard/read? (the student is free to ask the question to him/herself and not speak out the answer).

$\checkmark$ Does your own text contain any allusive elements? What are they?

$\checkmark$ How "independent" is your text from you?

$\checkmark$ Do you wish to change anything about your text having heard/read what the others have written/told?

$\checkmark$ How different/similar is your text to what everyone else has produced in terms of thematic development, composition, genre, background, etc.?

$\checkmark$ Make your contribution to the process of discussion by formulating your own question(s).

\section{Conclusion}

As a basically communicative phenomenon, at least because it is a way of thinking, reflection can serve for the broadening of the teaching and learning process, if used interactively. With the mechanism of asking questions to trigger the process, and as long as the latter is not taken as a formal type of activity but one that aims at revealing what is shared collectively and experienced individually, reflection is awareness of growth, gain due to exchange, and a way to discoveries (even if small).

\section{References:}

1. Airasian, P.W.; Cruikshank, K.A.; Mayer, R.E.; Pintrich, P.R.; Raths, J. \& Wittrock, M.C. (2001) A Taxonomy for Learning, Teaching, and Assessing: A Revision of Bloom's Taxonomy of Educational Objectives. Complete Edition. / Ed. by L.W. Anderson, D.R. Krathwohl. New York: Longman.

2. Engelhart, M.D.; Furst, E.J.; Hill, W.H. \& Krathwohl, D.R. (1956) Taxonomy of Educational Objectives: The Classification of Educational Goals. Handbook 1: Cognitive Domain. / Ed. by B.S. Bloom. New York: David Mc Kay.

3. Choy, S.Ch.; Oo, P.S. (Jan. 2012) Reflective Thinking and Teaching Practices: A Precursor for Incorporating Critical Thinking into the Classroom? // International Journal of Instruction. Vol. 5, N 1, pp. 167-182. 
4. Colley, B.M.; Bilics, A.R.; Lerch, C.M. (9-25-2012) A Key Component to Thinking Critically. // The Canadian Journal for the Scholarship of Teaching and Learning, Vol. 3, Issue 1, Article 2, pp. 1-19.

5. Girunyan, G. (2015) Cross-Cultural Perspective: An Attempt at Bimodal Reflection. // Multimodal Communication 20154 (2), pp. 151-165 (also available at: $<$ www.de-gruyter.com $>$ ).

6. Krathwohl, D.R. (2002) A Revision of Bloom's Taxonomy: An Overview. // Theory into Practice. Vol. 41, N 4. College of Education, The Ohio State University, pp. 212-218.

7. Mayer, R.E. (2002) Rote versus Meaningful Learning. // Theory into Practice. Vol. 41, N 4. College of Education, The Ohio State University, pp. 226-232.

8. Pintrich, P.R. (2002) The Role of Meta-Cognitive Knowledge in Learning, Teaching, and Assessing. // Theory into Practice. Vol. 41, N 4. College of Education, The Ohio State University, pp. 219-225.

9. Raths, J. (2002) Improving Instruction. // Theory into Practice, Vol. 41, N 4. College of Education, The Ohio State University, pp. 233-237.

10.Rodgers, C. (2002) Defining Reflection: Another Look at John Dewey and Reflective Thinking. // Teachers College Record. Vol. 104, N4. Teachers College, Columbia University, pp. 842-846.

11.Schmidt, D.J. (2013) Between Word and Image: Heidegger, Klee, and Gadamer on Gesture and Genesis. Bloomington and Indianapolis: Indiana University Press.

\section{ก.tQtipupujh ntinn guwnuGinu (Stipuunn unnåunumuluua nhunualujnılihg)}

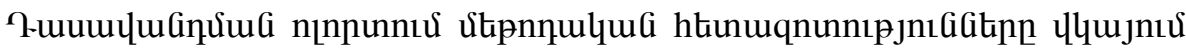

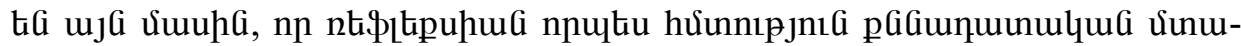

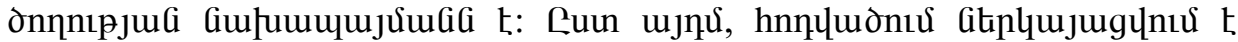

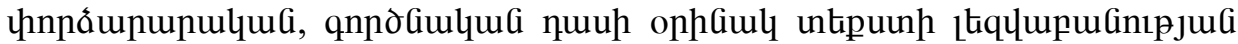

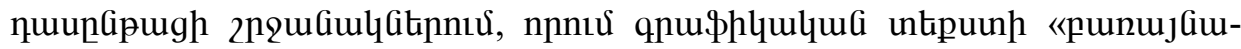

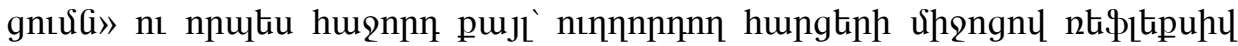

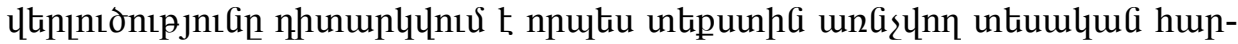

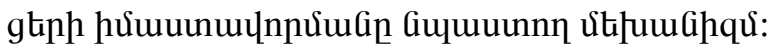

